\title{
Attitude of Indian Medical Students Towards Homosexuality
}

\author{
A Kar, S Mukherjee, A Ventriglio, D Bhugra
}

\begin{abstract}
Introduction: It is important to understand the attitude of medical students towards homosexuality, as this may affect patient care.

Methods: Year 2 and 3 students at Calcutta National Medical College, Kolkata, India were asked to selfadminister an 18-item questionnaire anonymously. Internal consistency of the questionnaire statements was high (Cronbach's alpha of 0.91). There were five responses for each statement: strongly agree, generally agree, unsure, generally disagree, and strongly disagree.

Results: Of 290 students, 270 (93.1\%) [148 males and 122 females] completed the questionnaire and were included in the analysis. Overall, $55.6 \%$ strongly disagreed that homosexuality was an illness; $70.8 \%$ agreed that homosexuals were capable of forming stable relationships. Only $31.1 \%$ believed that homosexual doctors would better understand homosexual patients. About $71.8 \%$ reported that talking about homosexuality did not embarrass them, and $81.8 \%$ believed that problems associated with homosexuality could be reduced if society was more liberal. Nonetheless, negative attitudes were reflected in the stereotypical image of homosexuality. About $15.9 \%$ of respondents believed that homosexuality was an illness; $24.8 \%$ considered homosexuals neurotic, $28.1 \%$ considered homosexuals promiscuous; and $8.2 \%$ thought that they posed a danger to children.

Conclusion: Although the overall attitude of Indian medical students towards homosexuality is positive, the percentage of students with negative attitudes remains quite high. Further work on the medical curriculum is needed to change these negative attitudes so that patients receive appropriate care.
\end{abstract}

Key words: Attitude; Homosexuality; Students, medical

Dr Anindya Kar, MBBS, Calcutta National Medical College, Kolkata, West Bengal, India.

Dr Shuvankar Mukherjee, MD, Assistant Professor, Department of Community Medicine, Calcutta National Medical College, Kolkata, West Bengal, India. Dr Antonio Ventriglio, MD, PhD, University of Foggia, Foggia, Italy. Prof Dinesh Bhugra, CBE MA, MSc, MBBS, FRCP, FRCPE, FRCPsych, FFPH, MPhil, PhD, Emeritus Professor of Mental Health and Cultural Diversity, Health Service and Population Research Department, Institute of Psychiatry, Psychology \& Neuroscience at King's College London, London, UK.

Address for correspondence: Dr Shuvankar Mukherjee, GEOS Cooperative, Flat No. 201, H-31, Baishnabghata Patuli Township, Kolkata, 700094, India. Email: shuvankar.commed@gmail.com

Submitted: 13 April 2017; Accepted: 8 November 2017

\section{Introduction}

Societal attitudes towards homosexuality vary greatly in different cultures and in different historical periods. Today, heterosexuality is seen as the norm worldwide. In many cultures, sexual minorities, including lesbians, gays, bisexuals, and transgenders (LGBT), are subject to stereotype and stigma. In India, such behaviours are illegal. In 2009, the Delhi High Court decriminalised homosexuality, but on 11 December 2013 the Supreme Court of India upheld section 377 of the Indian Penal Code that criminalises adult consensual same-sex contact. ${ }^{1,2}$ In April 2014, the Supreme Court of India granted constitutional recognition to transgenders as the third gender, and any discrimination towards them was considered a violation of their constitutional rights. ${ }^{3}$ There are different terms to indicate discriminatory behaviour towards sexual minorities. ${ }^{4}$ Doctors have a responsibility of care for stigmatised and discriminated groups. It is important to understand the attitude of medical students towards homosexuality in order to improve the healthcare system. Such studies remain inadequate, especially in Asian countries. 5

India is in transition demographically and environmentally and is facing triple disease burdens: an unfinished agenda of communicable diseases, emerging non-communicable diseases related to lifestyle, and emerging infectious diseases. ${ }^{6}$ There is evidence that LGBT people are disproportionately affected by certain medical conditions. ${ }^{4,7}$ Sexual and gender minority patients have experienced discrimination, stigmatisation, and even denial of care in the health system. ${ }^{8}$ A number of transgenders have had negative experiences with health professionals in government hospitals in India.7 According to the UNAIDS report in $2017,4.3 \%$ of the Indian population were estimated to be at high risk of AIDS; they were men having sex with men and transgenders. ${ }^{9}$ When physicians encounter LGBT patients, they may lack knowledge about 
and sensitivity to the needs and challenges of LGBT patients, and such content is underrepresented in medical school curricula. ${ }^{10}$ Development of curricula on culturally sensitive and competent health care for LGBT patients has been advocated. ${ }^{11}$ In India, there are no such guidelines or curricula for care for LGBT patients in the healthcare system. LGBT individuals share common social behaviours and choices that influence their health-seeking behaviour, preventive health measures, and disease risk. ${ }^{12}$ It is important to educate health care professionals to effectively assess and manage these patients without any prejudices and discrimination. Medical teachers play a pivotal role in better preparing medical students to handle these marginalised communities and thus reduce the healthcare disparities. ${ }^{13}$ Although medicine and psychiatry consider homosexual orientation a normal variant of human sexuality, the mental health fraternity and the government in India are yet to take a clear stand on the issues to change such prejudice in society. ${ }^{1}$ The physician-patient relationship plays a vital role in improving the health of individuals. ${ }^{14}$ Patients may choose not to reveal their sexual identity or orientation. Physicians need to be aware and sensitive when exploring this aspect to provide optimal care. ${ }^{15}$

Sexual orientation is a component of identity that includes a person's sexual and emotional attraction to another person and the behaviour and/or social affiliation that may result from this attraction. ${ }^{16}$ Gender identity is a person's deeply-felt, inherent sense of being a boy, a man, or male; a girl, a woman, or female; or an alternative gender. ${ }^{16}$ Transgender is an umbrella term to describe those whose gender identity and/or gender role does not conform to what is typically associated with their sex assigned at birth. ${ }^{16}$ In India, such individuals are often referred to as Hijra, but this identity does not match the modern western taxonomy of gender or sexual orientation. ${ }^{7}$

In the Bachelor of Medicine and Bachelor of Surgery curriculum in India, in the first year, physiology textbooks do not use the words or definitions of gender identity or sexual orientation. Some references and textbooks state that puberty is characterised by the development of attraction to the opposite sex, ${ }^{17}$ and that during puberty love for contact sports like football, wrestling, boxing, war games, and aggressiveness are seen in males. ${ }^{18}$ In the second year, a standard textbook on forensic medicine and toxicology writes, "In India, a class of male prostitutes called Eunuchs act as passive agents in sodomy among them there are two groups: Hijrahs and Zenana, who live separately". "Female homosexuality is known as tribadism or lesbianism. Many lesbians are masculine in type, possibly because of endocrine disturbances and are indifferent towards individuals of the opposite sex. The practice is usually indulged in by women who are mental degenerates or by those who suffer from nymphomania (excessive sexual desire)... lesbians who are morbidly jealous of one another, when rejected may commit homicide, suicide or both" ${ }^{19}$ In the third year, standard reference books on community medicine often interchangeably use the terms 'homosexual', 'men having sex with men', and 'high-risk populations' ${ }^{20}$ In the final year, a widely used textbook in psychiatry writes, "For seeking a change in sexual orientation, methods include: (1) psychoanalytic psychotherapy (especially when associated with personality issues), (2) behaviour therapy - aversion therapy (rarely used), covert sensitisation, systematic desensitisation (especially if there is phobia of heterosexual relationship), (3) supportive psychotherapy, (4) androgen therapy (occasionally)." "For seeking removal of distress only, methods include: (1) psychotherapy: psychoanalytic and supportive, depending on the personality character. (2) drug therapy: antidepressants and/or benzodiazepines for treatment of associated depression and anxiety". ${ }^{21}$

According to the World Psychiatric Association, provision of any intervention purporting to 'treat' something that is not a disorder is wholly unethical. ${ }^{22}$ This echoes the stand of the American Psychiatric Association and World Health Organization that have abandoned pathologising same sex orientation and behaviour. ${ }^{1}$

\section{Methods}

This cross-sectional study was approved by the ethics committee of the Calcutta National Medical College. Written informed consent was obtained from each participant. Year 1 and 4 students were excluded because of examinations and clinical postings, respectively. Year 2 and 3 students were asked to self-administer an anonymous, predesigned, pretested, structured questionnaire at two separate lectures in the morning and the afternoon. Two authors handed over the questionnaire to attendees following the lecture and collected the completed questionnaire in a sealed dropbox. Students were given 20 minutes to complete the questionnaire; discussion between students was not permitted.

The questionnaire was in English and modified from an earlier version used for British medical students. ${ }^{14}$ The adaption was approved by experts from the Departments of Community Medicine and Psychiatry. Some statements were excluded because of their doubtful validation in India where homosexual behaviour is illegal. Statements related to religious influences on attitudes, teaching in curricula, and therapies were excluded. The internal consistency of the questionnaire statements was high (Cronbach's alpha of 0.91). The questionnaire comprised 18 statements with 9 sub-statements and additional specific comments on the subject. There were five responses for each statement: strongly agree, generally agree, unsure, generally disagree, and strongly disagree. The phrasing of statements (positive or negative) was balanced in order to reduce response bias. Reverse scoring was performed for statements that showed unfavourable attitudes.

Data were analysed using SPSS (Windows version 20.0; IBM Corp, Armonk [NY], US). The mean attitude scores were compared between males and females and between year 2 and year 3 students using the Mann-Whitney $U$ test. A p value of $<0.05$ was considered statistically significant. 


\section{Results}

Of 290 students, $270(93.1 \%)$ completed the questionnaire and were included in the analysis. The remaining 20 students completed $<50 \%$ of the questionnaire. The mean \pm standard deviation age of the 148 male and 122 female respondents was $20.3 \pm 9.1$ years. The distribution of attitude scores was comparable between year $2(\mathrm{n}=133)$ and year $3(\mathrm{n}=$ $137)$ students $(84.3 \pm 13.58$ vs $86.0 \pm 19.66, p=0.194)$ and between male $(\mathrm{n}=148)$ and female $(\mathrm{n}=122)$ students $(85.0$ \pm 17.03 vs $85.3 \pm 16.88, \mathrm{p}=0.875)$.

Overall, $55.6 \% \quad(\mathrm{n}=151)$ strongly disagreed that homosexuality was an illness; 70.8\% (n=191) agreed that homosexuals were capable of forming stable relationships (Table). Only 31.1\% $(n=84)$ believed that homosexual doctors would better understand homosexual patients. About $71.8 \% \quad(n=194)$ reported that talking about homosexuality did not embarrass them, and $81.8 \%$

Table. Attitude of medical students towards homosexuality.

\begin{tabular}{|c|c|c|c|c|c|c|}
\hline \multirow[t]{2}{*}{ Statements } & \multicolumn{6}{|c|}{$\%$ of participants } \\
\hline & $\begin{array}{c}\text { Strongly } \\
\text { agree }\end{array}$ & $\begin{array}{l}\text { Generally } \\
\text { agree }\end{array}$ & Unsure & $\begin{array}{l}\text { Generally } \\
\text { disagree }\end{array}$ & $\begin{array}{l}\text { Strongly } \\
\text { disagree }\end{array}$ & $\begin{array}{l}\text { No } \\
\text { response }\end{array}$ \\
\hline \multicolumn{7}{|l|}{ I believe that homosexuality is: } \\
\hline Constitutionally determined & 28.9 & 3.3 & 15.6 & 19.3 & 29.6 & 3.3 \\
\hline Sexual orientation & 35.6 & 27.4 & 10.0 & 10.7 & 11.9 & 4.4 \\
\hline Acquired behaviour & 10.7 & 16.7 & 35.2 & 17.4 & 18.9 & 1.1 \\
\hline An illness & 11.1 & 4.8 & 0.4 & 23.7 & 55.6 & 3.3 \\
\hline $\begin{array}{l}\text { Homosexuality in general is a result of disturbed } \\
\text { relationship with one or both parents }\end{array}$ & - & 7.4 & 16.7 & 47.4 & - & 5.6 \\
\hline Homosexuals in general are neurotic & 4.4 & 20.4 & 16.7 & 33.3 & 25.2 & - \\
\hline Homosexuals in general are easily recognisable & 3.3 & 44.8 & 18.9 & 18.5 & 13.3 & 1.1 \\
\hline Homosexuals in general are promiscuous & 9.6 & 18.5 & 44.1 & 24.4 & 3.3 & - \\
\hline $\begin{array}{l}\text { Most male homosexuals have effeminate trait and } \\
\text { female homosexuals have masculine trait }\end{array}$ & 4.4 & 54.4 & 2.2 & 33.3 & 5.6 & - \\
\hline $\begin{array}{l}\text { In general homosexuals are capable of forming stable } \\
\text { relationships }\end{array}$ & 36.7 & 34.1 & 14.1 & 11.9 & 3.3 & - \\
\hline $\begin{array}{l}\text { I feel that homosexual doctor would treat homosexual } \\
\text { patients with better understanding }\end{array}$ & 18.9 & 12.2 & 40.7 & 23.7 & 4.4 & - \\
\hline Most male homosexuals would prefer to be females & 1.1 & 14.1 & 54.8 & 24.4 & 5.6 & - \\
\hline Most female homosexuals would prefer to be male & 0 & 20.4 & 40.7 & 11.1 & 27.8 & - \\
\hline Homosexuals should not be employed in schools & 2.2 & 9.6 & 9.6 & 25.2 & 53.3 & - \\
\hline Homosexuals are danger to children & 6.0 & 2.2 & 20.4 & 34.1 & 41.1 & - \\
\hline $\begin{array}{l}\text { Scientific material \& reading of homosexuality has not } \\
\text { really affected my views on subject }\end{array}$ & 23.2 & 45.6 & 21.1 & 5.9 & 4.1 & - \\
\hline $\begin{array}{l}\text { I feel that legal age of consent for homosexuals should } \\
\text { be the same as that of heterosexuals }\end{array}$ & 10.0 & 64.1 & 17.4 & 3.3 & 5.2 & - \\
\hline $\begin{array}{l}\text { I feel that problems associated with homosexuality could } \\
\text { be reduced if society were to liberalise its attitudes }\end{array}$ & 34.4 & 47.4 & 8.5 & 7.4 & - & 2.2 \\
\hline Talking about homosexuality does not embarrass me & 22.2 & 49.6 & 8.5 & 6.3 & 11.1 & 2.2 \\
\hline \multicolumn{7}{|l|}{ In my opinion causes of homosexuality are: } \\
\hline An innate predisposition & 6.7 & 35.6 & 24.1 & 23.7 & 6.7 & 3.3 \\
\hline Seduction experiences in childhood & 7.0 & 26.3 & 47.0 & 18.1 & 6.7 & 1.1 \\
\hline Fear of heterosexual activities & 1.1 & 22.6 & 18.9 & 46.3 & 7.8 & 3.3 \\
\hline Insufficient contact with the opposite sex at puberty & 1.1 & 5.6 & 54.8 & 25.2 & 11.1 & 2.2 \\
\hline Unsuccessful heterosexual experiences & 3.3 & 17.4 & 36.3 & 28.5 & 13.3 & 1.1 \\
\hline I do not really understand homosexuality & 5.6 & 27 & 11.9 & 47.8 & 6.7 & 1.1 \\
\hline
\end{tabular}


$(n=221)$ felt that problems associated with homosexuality could be reduced if society was more liberal. Nonetheless, negative attitudes were reflected in the stereotypical image of homosexuality, where $15.9 \% \quad(n=43)$ of respondents believed that homosexuality was an illness, $24.8 \%(n=67)$ thought they were neurotic, and $8.2 \%(n=22)$ thought they posed a danger to children.

\section{Discussion}

This is the first study from West Bengal to explore medical students' attitude towards homosexuality. One in eight respondents reported negative attitudes. These stereotypical attitudes have also been reported in medical students in Zagreb, Croatia. ${ }^{15}$ Attitude towards minorities may reflect a grudging and conditional acceptance of this group, as these attitudes are often contradictory and ambivalent. Some students regarded these sexualities as natural and believed that they should not be discriminated against because 'they can't help it'. For others, different sexualities were acceptable because the issue concerns the freedom or right to choose how one lives one's life. Nonetheless, both forms of acceptance are usually conditional as long as lesbians and gay men keep a low profile in public spaces. ${ }^{23}$ In the west, anti-homosexual attitudes, once considered the norm, have changed over time in many social and institutional settings. ${ }^{1}$ Nonetheless, heterosexism still denigrates and stigmatises all non-heterosexual forms of behaviour, identity, relationships, and communities. ${ }^{1}$ Homophobia is defined as an irrational fear or dislike of homosexuals. ${ }^{15}$ Homonegativity involves negative attitudes, values, and beliefs of the heterosexual majority about same-sex couples, lesbian women, and gay men. ${ }^{15}$

In our study, $22.6 \%$ of respondents disagreed that homosexuality is a sexual orientation and $15.9 \%$ respondents considered it an illness. These percentages are higher than those reported in studies in the West..$^{14,15,24,25}$ Our medical students may feel 'comfortable' with LGBT issues in theory but the reality may be different. This cognitive dissonance may create problems for clinicians when managing patients with variance in sexual orientation. ${ }^{14}$

About $81.8 \%$ of respondents felt that problems associated with homosexuality could be reduced if society was more liberal, as legal proscriptions mould attitudes. ${ }^{26}$ About $74.1 \%$ of respondents felt that the legal age of consent for homosexuals should be the same as that for heterosexuals. Nonetheless, modern medicine in India remains reluctant to emphatically support liberal sexual norms, because of local religious and social orthodoxy. ${ }^{27}$ About $68.8 \%$ of respondents felt that their attitudes had not been affected by scientific studies on homosexuality. Teaching of sexuality to medical professionals needs to be perceptive to the issues faced by people with different sexual orientations and identities. Clinical services for people with such issues and concerns need to be sensitive in order to provide holistic care. ${ }^{1}$

About $70.8 \%$ of respondents felt that homosexuals were capable of forming stable relationships in general. Children of lesbian or gay parents are not significantly disadvantaged relative to children of heterosexual parents..$^{28}$

About $58.8 \%$ of respondents believed that male homosexuals have effeminate traits and female homosexuals have masculine traits. About $48.1 \%$ of respondents felt that homosexuals in general are easily recognisable. Nonetheless, gay men and lesbian women are indistinguishable from straight men and women in most respects, except sexual preference. ${ }^{29}$

Despite a more positive public opinion towards homosexuals, institutional and personal hostility towards homosexuals remains substantial, and negative stereotypes suchasexhibition of genderatypical traits, sexual promiscuity, and predatory sexual tendencies persist. ${ }^{30}$ About $27.4 \%$ of respondents felt homosexuality to be an acquired behaviour and about $28.1 \%$ believed homosexuals to be promiscuous. The AIDS epidemic gave rise to homophobic attitudes in the medical community, and negative and discriminatory attitudes in certain healthcare workers. ${ }^{15}$ Discrimination in healthcare settings is detrimental to the health of minority individuals as well as to their help-seeking behaviour and adherence to treatment. ${ }^{31}$ Oppressive social structures and inequalities have been implicated in perpetuating not only the AIDS epidemic but also the rates of anal cancer, hepatitis B, human papillomavirus, and lymphogranulma venereum infections, syphilis, gonorrhoea, and hepatitis C. ${ }^{32}$ In the Indian male-to-female transgender population, the prevalence of HIV is estimated to be $11 \%$ to $78 \% .^{33}$

About $71.8 \%$ of respondents were not embarrassed to talk about homosexuality. Despite the overwhelmingly accepting attitudes, some individuals are reluctant to support homosexuals' human rights. ${ }^{24}$ Efforts to address prejudices, among other covert biases, are needed to facilitate open discussions and thereby improve care. ${ }^{25}$ In almost all cultures, men hold a more negative attitude towards sexual minorities and tend to be more judgemental about male than female homosexuality. ${ }^{24}$

Our study has several limitations. The attitude of medical students was assessed using an 18-item questionnaire only. Certain parameters such as sociodemographic profile, sexual orientation, political and religious beliefs were omitted to avoid any controversy considering homosexuality is illegal in India. Students may have a more positive, liberal attitude but in reality they exhibit a negative attitude. It would be helpful to have qualitative data to supplement quantitative findings. The sample was from one medical school only and may not be representative of the entire medical student population in India; multi-centre studies are warranted.

\section{Conclusion}

Although the overall attitude of Indian medical students towards homosexuality is positive, the percentage of students with negative attitudes remains quite high. Further work on the medical curriculum is needed to change these 
negative attitudes so that patients receive appropriate care.

\section{Acknowledgments}

We would like to thank the head of the institution for allowing us to carry out the survey and the participants. We would also like to thank the professors of the Department of Psychiatry and Department of Community Medicine for reviewing the questionnaire.

\section{Declaration}

The authors have no conflicts of interest to disclose.

\section{References}

1. Rao TS, Jacob KS. Homosexuality and India. Indian J Psychiatry 2012;54:1-3. Eross re

2. Somasundaram O, Tejus Murthy AG. Homosexuality - leaves from antiquity: lesbian, gay, bisexual, and transgender population: a Tamil perspective. Indian J Psychiatry 2016;58:336-8. Eross re

3. Babbar SK. The socio-legal exploitation of the third gender in India. IOSR J Humanit Soc Sci 2016;21:12-8.

4. Math SB, Seshadri SP. The invisible ones: sexual minorities. Indian J Med Res 2013;137:4-6.

5. Wu KK, Leung EY, Leung AY. A survey on same-sex attraction in secondary school adolescents: prevalence and psychosocial factors. Hong Kong J Psychiatry 2008;18:15-22.

6. Chauhan LS. Public health in India: issues and challenges. Indian J Public Health 2011;55:88-91. cross ret

7. Chettiar A. Problems faced by Hijras (male to female transgenders) in Mumbai with reference to their health and harassment by the police. Int J Soc Sci Humanity 2015;5:752-9. Eross re

8. Müller A. Health for all? Sexual orientation, gender identity, and the implementation of the right to access to health care in South Africa. Health Hum Rights 2016;18:195-208.

9. UNAIDS Data 2017. Available from: http://www.unaids.org/sites/ default/files/media_asset/20170720_Data_book_2017_en.pdf. Accessed 13 April 2017.

10. Sequeira GM, Chakraborti C, Panunti BA. Integrating lesbian, gay, bisexual, and transgender (LGBT) content into undergraduate medical school curricula: a qualitative study. Ochsner J 2012;12:379-82.

11. Hatzenbuehler ML, O'Cleingh C, Grasso C, Mayer K, Safren S, Bradford J. Effect of same-sex marriage laws on health care use and expenditures in sexual minority men: a quasi-natural experiment. Am J Public Health 2012;102:285-91. cross ref

12. Kaufman MR, Cornish F, Zimmerman RS, Johnson BT. Health behavior change models for HIV prevention and AIDS care: practical recommendations for a multi-level approach. J Acquir Immune Defic Syndr 2014;66(Suppl 3):S250-8. cross ret

13. Chinchilla M, Arcaya MC. Using Health Impact Assessment as an interdisciplinary teaching tool. Int $\mathrm{J}$ Environ Res Public Health
2017;14:1-13.

14. Parker A, Bhugra D. Attitudes of British medical students towards male homosexuality. Sex Relatsh Ther 2000;15:141-9. cross ret

15. Grabovac I,Abramovic M,Komlenovic G, Milosevic M, Mustajbegovic J. Attitudes towards and knowledge about homosexuality among medical students in Zagreb. Coll Antropol 2014;38:39-45.

16. American Psychological Association. Guidelines for psychological practice with transgender and gender nonconforming people. Am Psychol 2015;70:832-64. Eross re

17. Mahapatra AB. Essentials of Medical Physiology. 3rd edition. Kolkata: Current Books International; 2010.

18. Chaudhuri SK. Concise Medical Physiology. 5th edition. Kolkata: New Central Book Agency; 2011.

19. Reddy KS, Murty OP. The Essentials of Forensic Medicine and Toxicology. 33rd edition. New Delhi: Jaypee Publishers; 2014.

20. Park K. Park's Textbook of Preventive and Social Medicine. 22nd edition. Jabalpur: Banarsidas Bhanot Publishers; 2013.

21. Ahuja N. A Short Textbook of Psychiatry. 7th edition. New Delhi: Jaypee Brothers Medical Publishers; 2011. cross ret

22. Bhugra D, Eckstrand K, Levounis P, Kar A, Javate KR. WPA Position Statement on Gender Identity and Same-Sex Orientation, Attraction and Behaviours. World Psychiatry 2016;15:299-300. Eross ret

23. Valentine G, McDonald I. Understanding Prejudice: Attitudes Towards Minorities. London: Stonewall; 2004.

24. Dunjić-Kostić B, Pantović M, Vuković V, Randjelović D, TotićPoznanović S, Damjanović A, et al. Knowledge: a possible tool in shaping medical professionals' attitudes towards homosexuality. Psychiatr Danub 2012;24:143-51.

25. Matharu K, Kravitz LR, McMahon TG, Wilson DM, Fitzgerald TF. Medical students' attitudes toward gay men. BMC Med Educ 2012;12:71. cross re

26. Collier KL, Bos HM, Sandfort TG. Intergroup contact, attitudes toward homosexuality, and the role of acceptance of gender non-conformity in young adolescents. J Adolesc 2012;35:899-907. Eross re

27. Sathyanarayana Rao TS, Rao GP, Raju MS, Saha G, Jagiwala M, Jacob KS. Gay rights, psychiatric fraternity, and India. Indian J Psychiatry 2016;58:241-3. eross re

28. Marks L. Same-sex parenting and children's outcomes: a closer examination of the American psychological association's brief on lesbian and gay parenting. Soc Sci Res 2012;41:735-51. cross re

29. Posner RA. Eighteen years on: a re-review. Yale Law J 2015; 125:53342.

30. Felmlee D, Orzechowicz D, Fortes C. Fairy tales: attraction and stereotypes in same-gender relationships. Sex Roles 2010;62:22640. Eross re

31. Shippee T, Henning-Smith C, Shippee N, Pintor JK, Call KT, McAlpine D, et al. Discrimination in medical settings and attitudes toward complementary and alternative medicine: the role of distrust in conventional providers. J Health Dispar Res Pract 2013;6:30-45.

32. Halkitis NP. Discrimination and homophobia fuel the HIV epidemic in gay and bisexual men. Psychol AIDS Exch Newsl 2012;1:4-11.

33. Sinha A, Goswami DN, Haldar D, Mallik S, Bisoi S, Karmakar PR. Sexual behavior of transgenders and their vulnerability to HIV/AIDS in an Urban Area of Eastern India. Indian J Public Health 2017;61:1413. 